\title{
Clinical Usefulness of Sonoelastography in Infants With Congenital Muscular Torticollis
}

\author{
Seong Kyung Hong, $\mathrm{MD}^{1}$, Jin Won Song, $\mathrm{MD}^{1}$, Seung Beom Woo, $\mathrm{MD}^{1}$, \\ Jong Min Kim, $\mathrm{MD}^{1}$, Tae Eun Kim, $\mathrm{MD}^{2}$, Zee Ihn Lee, $\mathrm{MD}^{1}$ \\ Departments of ${ }^{1}$ Rehabilitation Medicine and ${ }^{2}$ Radiology, Daegu Fatima Hospital, Daegu, Korea
}

Objective To evaluate the clinical usefulness of sonoelastography in infants with congenital muscular torticollis (CMT).

Methods The medical records of 215 infants clinically diagnosed with CMT were retrospectively reviewed. Fiftythree infants met the inclusion criteria as follows: 1) infants diagnosed as CMT with a palpable neck mass before 3 months of age, 2) infants who were evaluated initially by both B-mode ultrasonography and sonoelastography, and 3) infants who had received physical therapy after being diagnosed with CMT. We checked the thickness of the sternocleidomastoid (SCM) muscles in B-mode ultrasonography, strain ratio of the SCM muscles in sonoelastography, and treatment duration. We evaluated the correlation between the treatment duration and the following factors: SCM muscle thickness, ratio of SCM muscle thickness on the affected to unaffected side (A/U ratio), and strain ratio.

Results Both the thickness of the affected SCM muscle and the A/U ratio did not show significant correlation with the treatment duration $(\mathrm{p}=0.66, \mathrm{p}=0.90)$. The strain ratio of the affected SCM muscle was significantly greater than that of the unaffected SCM muscle $(\mathrm{p}<0.001)$, and the strain ratio showed significant correlation with the treatment duration $(\mathrm{p}=0.001)$.

Conclusion Sonoelastography may be a useful adjunctive tool to B-mode ultrasonography for evaluating infants with CMT, especially when predicting their rehabilitation outcomes.

Keywords Congenital muscular torticollis, Sonoelastography, Prognosis

\section{INTRODUCTION}

Congenital muscular torticollis (CMT) is considered as

Received May 7, 2015; Accepted July 29, 2015

Corresponding author: Zee Ihn Lee

Department of Rehabilitation Medicine, Daegu Fatima Hospital, 99 Ayang-ro, Dong-gu, Daegu 41199, Korea

Tel: +82-53-940-7823, Fax: +82-53-954-7417, E-mail: zilee@hanmail.net

(c) This is an open-access article distributed under the terms of the Creative Commons Attribution Non-Commercial License (http://creativecommons. org/licenses/by-nc/4.0) which permits unrestricted noncommercial use, distribution, and reproduction in any medium, provided the original work is properly cited.

Copyright $\odot 2016$ by Korean Academy of Rehabilitation Medicine a neck deformity that involves contracture of the sternocleidomastoid (SCM) muscle. The characteristic clinical features of CMT include ipsilateral tilt of head, contralateral rotation of the face and chin, and palpable neck mass [1-3].

The initial treatment for CMT is physical therapy, including manual stretching exercise and massage. More than $90 \%$ of the infants with CMT reach full recovery through physical therapy. Contracture of the SCM muscle can persist despite physical therapy, with consequent craniofacial asymmetry, plagiocephaly, or scoliosis. In 
refractory cases, surgical intervention may also be indicated [4-9].

Conventional B-mode ultrasonography has been used widely for diagnosing mass within the SCM muscle in infants with CMT. Muscle thickness, echogenicity, and transverse and longitudinal extents of involvement are evaluated by conventional B-mode ultrasonography. Many researchers have studied the correlation between the B-mode finding of SCM muscle and treatment duration to investigate the rehabilitation outcomes in infants with CMT. Nevertheless, the results from the previous studies have been inconsistent [9-12].

Sonoelastography has recently been used for evaluating tissue stiffness in real-time. This imaging technique is based on the principle that tissue compression induces strain (displacement) within the tissue and the strain is smaller in harder tissue than in softer tissue $[13,14]$.

In this study, we investigated whether the sonoelastography would be beneficial for predicting the outcomes of treatments in infants with CMT.

\section{MATERIALS AND METHODS}

We investigated the medical record of 215 infants clinically diagnosed with CMT from January 2013 to December 2014. Inclusion criteria were as follows: 1) infants diagnosed as CMT with a palpable neck mass before 3 months of age, 2) infants evaluated initially by both Bmode ultrasonography and sonoelastography, 3) infants who had received conservative treatment after being diagnosed with CMT. Exclusion criteria were as follows: 1) infants with neurodevelopmental disorders, 2) congenital anomalies of the cervical spine, 3) spasmodic, neurogenic and ocular torticollis, and 4) infants lost to followup.

We obtained the data as follows: age at diagnosis, sex, affected side, thickness of SCM muscles and ratio of SCM muscle thickness on the affected to unaffected side $(\mathrm{A} / \mathrm{U}$ ratio) in B-mode imaging, strain ratio of SCM muscles in sonoelastogram, and treatment duration.

B-mode ultrasonography and sonoelastography were performed by an experienced musculoskeletal radiologist using the Philips iU 22 ultrasound system (Philips Health Care, Andover, MA, USA) with an L12-5 linear transducer. Neck ultrasonography was conducted on infants in supine position following rotation of their head to the op- posite side. Both transverse and longitudinal views of the SCM muscle were obtained from conventional B-mode imaging. After B-mode ultrasonographic assessment, the same radiologist conducted sonoelastographic evaluation of the SCM muscle in the transverse and longitudinal views. The force applied to neck with the probe was adjusted in accordance with the indicator on the monitor, which presented optimal strain within the region of interest (ROI) in the color-coded image. The ultrasound images were transferred to a picture archive and communication system and the results were subsequently read by the same radiologist. The affected and unaffected SCM muscles' thickness and the distance from the most superficial to the deepest aponeuroses in the thickest region of the SCM muscle from the transverse view were measured (Fig. 1). For color-coded image in sonoelastogram, the relative stiffness of the neck tissue was represented by the colors ranging from red (soft, high elasticity) to blue (hard, low elasticity) within a continuous spectrum. Strain ratio is the relative stiffness of the SCM muscle compared to that of the subcutaneous tissue. A circular ROI was placed onto the subcutaneous fat layer as reference region and another circular ROI was placed on the SCM muscle in the transverse view. The strain ratio between both the ROIs was calculated automatically by the built-in software in the ultrasound system, which divided the ROI of the subcutaneous tissue by the ROI of the muscle [15] (Fig. 2). The higher value of the strain ratio indicates less elasticity of the tissues.

For conservative treatment, manual stretching and massage on the affected SCM muscle were performed

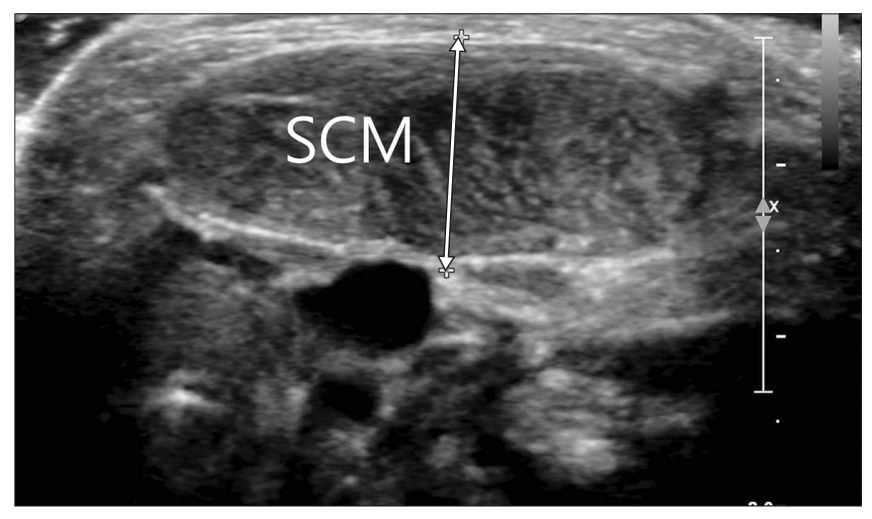

Fig. 1. Transverse view of the sternocleidomastoid (SCM) muscle in B-mode ultrasonogram. White arrow indicates thickness of the SCM muscle. 

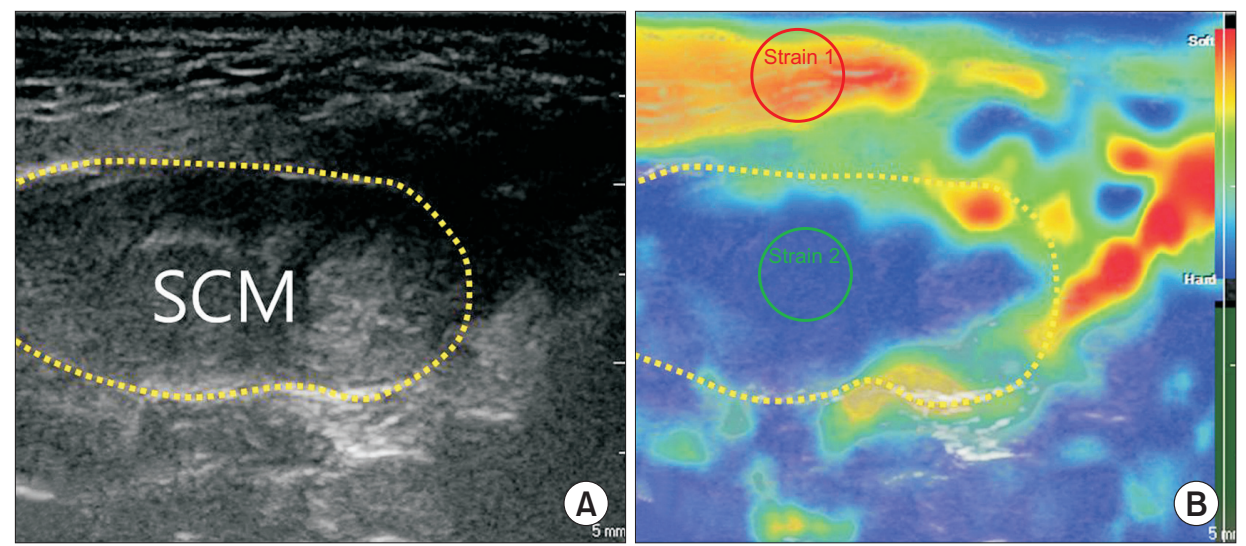

Fig. 2. Transverse view of sternocleidomastoid (SCM) muscle in B-mode ultrasonogram (A) and sonoelastogram (B). Each yellow dotted circle is the cross-sectional area of SCM muscle. In sonoelastogram (B), the colors ranging from red (soft) to blue (hard) represent relative stiffness of the tissue. Red circle (strain 1) indicates region of interest (ROI) of subcutaneous tissue (reference tissue), and green circle (strain 2) is ROI of SCM muscle.

twice a week for 30 minutes by a specialized physical therapist. In addition, home exercise was performed with the infants' parents. When differences between both sides in the range of motion (ROM) of cervical rotation and side-bending were $<5^{\circ}$, the treatment was regarded as successful, and physical therapy was discontinued. Cervical ROM was measured with a Baseline 12-1076 arthrodial goniometer (Fabrication Enterprises, White plains, NY, USA) on infants in supine position. The ROM of cervical rotation was measured by rotating the infants' head to both sides, and the ROM of cervical side-bending was determined by measuring the deviated degree from neutral position. Treatment duration was defined as the period between the first visit day and the last day of physical therapy.

Statistical analysis was performed using the SPSS ver. 20.0 software program (IBM SPSS Inc., Armonk, NY, USA). Difference in muscle thickness and strain ratio between right and left SCM muscles was evaluated by Wilcoxon signed rank test. The Spearman correlation test was used to assess the correlation between treatment duration and the following factors: SCM muscle thickness, A/U ratio, and strain ratio. A p-value of $<0.05$ was regarded as statistical significance.

The study was approved by the Institutional Review Board and informed parental consent was waived due to the characteristic of retrospective study.
Table 1. Demographic factors of infants with the CMT enrolled in this study $(n=53)$

\begin{tabular}{lc}
\hline & Value \\
\hline Sex & \\
Male & $35(66)$ \\
Female & $18(34)$ \\
\hline Affected side & $24(45)$ \\
Right & $29(55)$ \\
Left & $30.92 \pm 21.72$ \\
\hline Age at diagnosis (day)
\end{tabular}

Values are presented as number (\%) or mean \pm standard deviation.

CMT, congenital muscular torticollis.

\section{RESULTS}

Among the 215 infants, 53 (35 males and 18 females) were enrolled in the study. The mean age at diagnosis was $30.92 \pm 21.72$ days. Twenty-four infants were affected to right side, and 29 infants were affected to left side (Table 1).

Mean thickness of the affected SCM muscle was $1.26 \pm 0.22 \mathrm{~cm}$, and that of the unaffected SCM muscle was $0.86 \pm 0.33 \mathrm{~cm}$. $\mathrm{A} / \mathrm{U}$ ratio was $1.88 \pm 0.43$. In strain ratio, the affected side was $2.50 \pm 1.21$, and the unaffected side was $0.86 \pm 0.33$. Both the thickness and the strain ratio of the affected SCM muscle were significantly greater than those of the unaffected SCM muscle $(\mathrm{p}<0.001)$ (Table 2).

The treatment duration ranged from 72 to 322 days (mean duration, 157.13 \pm 52.85 days). The thickness of 
Table 2. The findings in B-mode ultrasonography and sonoelastography of the SCM muscles

\begin{tabular}{lccc}
\hline & $\begin{array}{c}\text { Affected } \\
\text { side }\end{array}$ & $\begin{array}{c}\text { Unaffected } \\
\text { side }\end{array}$ & p-value \\
\hline $\begin{array}{l}\text { Muscle } \\
\text { thickness }(\mathrm{cm})\end{array}$ & $1.26 \pm 0.22$ & $0.68 \pm 0.93$ & $0.000^{*}$ \\
Strain ratio & $2.50 \pm 1.21$ & $0.86 \pm 0.33$ & $0.000^{*}$ \\
\hline
\end{tabular}

Values are presented as mean \pm standard deviation.

SCM, sternocleidomastoid.

${ }^{*} \mathrm{p}<0.001$, Wilcoxon signed-rank test.

Table 3. The correlation between the ultrasonographic findings and the treatment duration

\begin{tabular}{lcc}
\hline \multirow{1}{*}{ Variable } & \multicolumn{2}{c}{$\begin{array}{c}\text { Treatment duration } \\
(\mathbf{1 5 7 . 1 3} \pm \mathbf{5 2 . 8 5} \text { days })\end{array}$} \\
\cline { 2 - 3 } & $\begin{array}{c}\text { Correlation } \\
\text { coefficient }\end{array}$ & p-value \\
\hline $\begin{array}{c}\text { SCM thickness } \\
(1.26 \pm 0.22 \mathrm{~cm})\end{array}$ & 0.062 & 0.66 \\
A/U ratio $(1.88 \pm 0.43)$ & -0.018 & 0.90 \\
\hline Stain ratio $(2.50 \pm 1.21)$ & 0.436 & $0.001^{*}$ \\
\hline
\end{tabular}

Values are presented as mean \pm standard deviation.

SCM, sternocleidomastoid; A/U ratio, ratio of SCM muscle thickness on the affected to unaffected side.

${ }^{*} \mathrm{p}<0.01$, Spearman correlation test.

the affected SCM muscle as well as the A/U ratio did not show significant correlation with the treatment duration $(\mathrm{p}=0.66, \mathrm{p}=0.90)$. The strain ratio of the affected SCM muscle was significantly correlated with treatment duration ( $\mathrm{p}=0.001)$ (Table 3, Fig. 3).

\section{DISCUSSION}

Many researchers have studied the relationship between rehabilitation outcome and variables associated with SCM muscle in B-mode ultrasonography. Some studies have correlated thickness of SCM muscle with treatment duration, whereas the results of some studies have been inconclusive. Jung et al. [10] reported that the thickness of the SCM and A/U ratio showed significant correlation with the treatment duration. Han et al. [11] demonstrated that the treatment duration was not affected by the thickness of SCM muscle, while A/U ratio affects the treatment duration. Lee et al. [9] founded that both the thickness of SCM muscle and A/U ratio did not significantly correlate with the treatment duration. In this

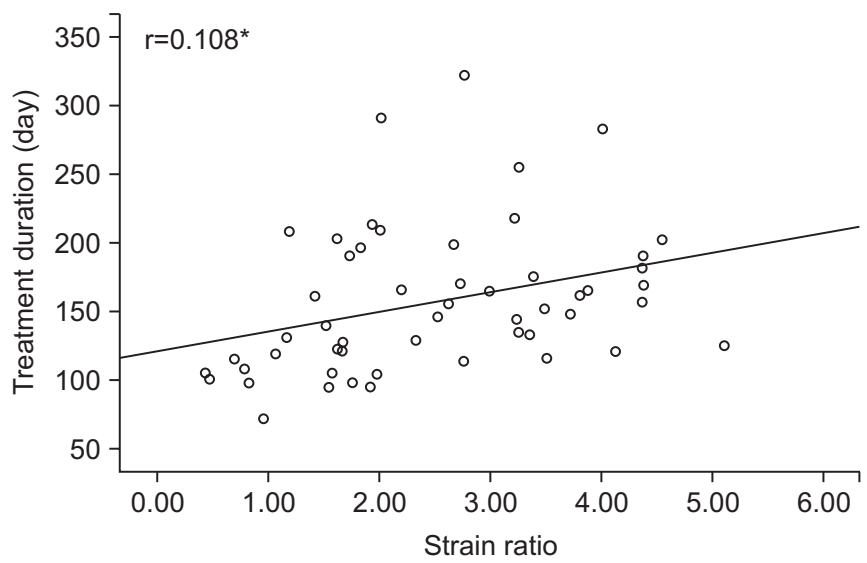

Fig. 3. Correlation between strain ratio and treatment duration in a scatter plot. ${ }^{*} \mathrm{p}<0.01$, Spearman correlation test.

study, both SCM muscle thickness and A/U ratio were not related to treatment duration. Han et al. [11] reported that the relationship between SCM muscle thickness and rehabilitation outcome in infants with CMT is inconsistent, because thickness of the SCM muscle can be influenced by development and age.

The cause of CMT is considered as contracture due to fibrosis of SCM muscle. In histologic studies, resected surgical specimens of SCM muscle have demonstrated fibrosis of muscle fibers, and the basic abnormality is known as endomysial fibrosis caused by migration of fibroblasts and deposition of collagen around individual muscle fibers [16-18].

Sonoelastography is a recently developed technique for evaluating tissue elasticity in real time. This technique has been applied based on the pathogenesis associated with tissue stiffness in various musculoskeletal disorders. Drakonaki and Allen [19] reported that sonoelastography could be used for evaluating the change of muscle stiffness in congenital muscular dystrophy. Sconfienza et al. [20] reported that in patient with plantar fasciitis, sonoelastography increases diagnosis with B-mode ultrasonography, and assists in cases of equivocal B-mode ultrasonographic findings. Klauser et al. [21] reported that sonoelastography is useful for predicting the histopathological degeneration in Achilles tendinosis.

While there have been studies on the application of sonoelastography in infants with CMT, they have been limited in number and method. Lee et al. [22] studied the role of sonoelastography for diagnosing CMT by using a scoring system based on colors in the color-coded im- 
age of sonoelastogram. They reported that SCM muscle in infants with CMT had lower elasticity, as compared with normal SCM muscle, and sonoelastography could differentiate a subtle change of echogenicity on B-mode image. Kwon and Park [23] evaluated the role of sonoelastography for predicting the outcomes of rehabilitation in infants with CMT by using a scoring system based on colors and intensity of pixels in the color-coded image of sonoelastogram. In their study, the infants with CMT were divided into 2 groups based on findings of both Bmode image and sonoelastogram, and the results indicated that both thicker mass in B-mode image and higher scoring and intensity of pixels in sonoelastogram had poorer treatment outcome.

Sonoelastography can be conducted along with the Bmode ultrasonography, which is useful for evaluating mass of SCM muscle. In our study, we aimed to determine the factor that correlated with rehabilitation outcome of infants with CMT, using sonoelastography as an adjuvant tool to B-mode ultrasonography. We evaluated stiffness of SCM muscle in infants with CMT by using strain ratio, the semi-quantitative ratio scale instead of the scoring system. This study indicated that the affected SCM muscle in infants with CMT had lower elasticity than unaffected SCM muscle, and the SCM muscle with lower elasticity had longer treatment duration in infants with CMT. This is the first study that evaluated the direct relationship between elasticity of SCM muscle and treatment duration in infants with CMT. Therefore, sonoelastography ancillary to B-mode image provides more information for planning the diagnostic and treatment strategy in infants with CMT.

This study had a few limitations, including the small number of infants and retrospective design. Furthermore, ultrasonographic measurement was conducted by a single operator without evaluating inter-rater reliability.

In conclusion, sonoelastography may be a useful adjunctive tool to B-mode ultrasonography for evaluating infants with CMT, especially when predicting the rehabilitation outcomes of infants with CMT.

\section{CONFLICT OF INTEREST}

No potential conflict of interest relevant to this article was reported.

\section{REFERENCES}

1. Ling CM, Low YS. Sternomastoid tumor and muscular torticollis. Clin Orthop Relat Res 1972;86:144-50.

2. Cheng JC, Au AW. Infantile torticollis: a review of 624 cases. J Pediatr Orthop 1994;14:802-8.

3. Porter SB, Blount BW. Pseudotumor of infancy and congenital muscular torticollis. Am Fam Physician 1995;52:1731-6.

4. Yim SY, Lee IY, Park MC, Kim JH. Differential diagnosis and management of abnormal posture of the head and neck. J Korean Med Assoc 2009;52:705-18.

5. Cheng JC, Tang SP, Chen TM. Sternocleidomastoid pseudotumor and congenital muscular torticollis in infants: a prospective study of 510 cases. J Pediatr 1999;134:712-6.

6. Brans J, Aramideh M, Bosch A, Speelman H. Late presentation of congenital muscular torticollis: a nondystonic cause of torticollis. J Neurol 1996;243:354-6.

7. Singer C, Green BA, Bruce JH, Bowen BC, Weiner WJ. Late presentation of congenital muscular torticollis: use of MR imaging and CT scan in diagnosis. Mov Disord 1994;9:100-3.

8. Yu CC, Wong FH, Lo LJ, Chen YR. Craniofacial deformity in patients with uncorrected congenital muscular torticollis: an assessment from three-dimensional computed tomography imaging. Plast Reconstr Surg 2004;113:24-33.

9. Lee JY, Koh SE, Lee IS, Jung H, Lee J, Kang JI, et al. The cervical range of motion as a factor affecting outcome in patients with congenital muscular torticollis. Ann Rehabil Med 2013;37:183-90.

10. Jung AY, Kang EY, Lee SH, Nam DH, Cheon JH, Kim HJ. Factors that affect the rehabilitation duration in patients with congenital muscular torticollis. Ann Rehabil Med 2015;39:18-24.

11. Han SJ, Shin BM, Lee JM, Yoon TS. Factors affecting rehabilitation outcome of congenital muscular torticollis. J Korean Acad Rehabil Med 2010;34:643-9.

12. Han JD, Kim SH, Lee SJ, Park MC, Yim SY. The thickness of the sternocleidomastoid muscle as a prognostic factor for congenital muscular torticollis. Ann Rehabil Med 2011;35:361-8.

13. Ophir J, Cespedes I, Ponnekanti H, Yazdi Y, Li X. Elastography: a quantitative method for imaging the elasticity of biological tissues. Ultrason Imaging 
1991;13:111-34.

14. Niitsu M, Michizaki A, Endo A, Takei H, Yanagisawa O. Muscle hardness measurement by using ultrasound elastography: a feasibility study. Acta Radiol 2011;52:99-105.

15. Ariji Y, Katsumata A, Hiraiwa Y, Izumi M, Iida Y, Goto $\mathrm{M}$, et al. Use of sonographic elastography of the masseter muscles for optimizing massage pressure: a preliminary study. J Oral Rehabil 2009;36:627-35.

16. Kim MO, Kim SJ. Results of the conservative management in congenital musculartorticollis. J Korean Acad Rehabil Med 1992;16:42-50.

17. Do TT. Congenital muscular torticollis: current concepts and review of treatment. Curr Opin Pediatr 2006;18:26-9.

18. Lee YT, Yoon K, Kim YB, Chung PW, Hwang JH, Park YS, et al. Clinical features and outcome of physiotherapy in early presenting congenital muscular torticollis with severe fibrosis on ultrasonography: a prospective study. J Pediatr Surg 2011;46:1526-31.
19. Drakonaki EE, Allen GM. Magnetic resonance imaging, ultrasound and real-time ultrasound elastography of the thigh muscles in congenital muscle dystrophy. Skeletal Radiol 2010;39:391-6.

20. Sconfienza LM, Silvestri E, Orlandi D, Fabbro E, Ferrero G, Martini C, et al. Real-time sonoelastography of the plantar fascia: comparison between patients with plantar fasciitis and healthy control subjects. Radiology 2013;267:195-200.

21. Klauser AS, Miyamoto H, Tamegger M, Faschingbauer R, Moriggl B, Klima G, et al. Achilles tendon assessed with sonoelastography: histologic agreement. Radiology 2013;267:837-42.

22. Lee SY, Park HJ, Choi YJ, Choi SH, Kook SH, Rho MH, et al. Value of adding sonoelastography to conventional ultrasound in patients with congenital muscular torticollis. Pediatr Radiol 2013;43:1566-72.

23. Kwon DR, Park GY. Diagnostic value of real-time sonoelastography in congenital muscular torticollis. J Ultrasound Med 2012;31:721-7. 